\title{
Entrevista com Ricardo Beliel
}

Ricardo Beliel é graduado em Jornalismo (FACHA) e pós-graduado em Fotografia nas Ciências Sociais (UCAM), em Comunicação e Políticas Públicas (UFRJ) e em Teoria e Prática da Educação de Nível Superior (ESPM). Foi professor na Escola Superior de Propaganda e Marketing (ESPM), na Universidade Estácio de Sá e no Ateliê da Imagem. Também foi jurado do Prêmio PETROBRAS de Jornalismo, em 2018.

Ricardo Beliel iniciou seu interesse pelas artes quando foi aluno do curso de Gravura, ministrado por Fayga Ostrower, Ana Letycia e Ruddy Pozzati, no MAM do Rio de Janeiro e no Centro de Estudos de Arte Ivan Serpa. Em 1973 começa a fotografar, trabalhando com músicos como Caetano Veloso, Gilberto Gil, Egberto Gismonti e 0 Terço. Em 1976, entra para o jornalismo como fotógrafo contratado do jornal 0 Globo, passando depois pela Manchete, Placar, Fatos e Fotos, Veja, Isto É, agência F-4, Manchete Esportiva, Jornal do Brasil, Greenpeace e 0 Estado de São Paulo. Foi editor de Fotografia da revista Manchete e subeditor no jornal Lance, do qual participou da equipe fundadora. Durante seis anos, fez parte da agência GLMR \& Saga Associés em Paris, produzindo reportagens fotográficas na América Latina e na África. Como jornalista e fotógrafo independente tem trabalhos publicados em Grands Reportages, Figaro Magazine, Time, National Geographic, Victory, San Francisco Chronicle, Houston Chronicle, Colors, Geo, La Vanguardia, Los Tiempos, Ícaro, Terra, Próxima Viagem, Marie Claire, Época, Vice, Nova Escola, Placar, Angola Hoje, entre outras revistas e jornais.

Recebeu da Organização Internacional de Jornalistas o prêmio InterPressPhoto e da Confederação de Jornalistas da União Soviética o prêmio Alexander Rodchenko, ambos em 1991. Foi finalista cinco vezes do Prêmio Abril de Jornalismo, sendo vencedor em três anos consecutivos. Em 1997, foi finalista no Prêmio Esso de Jornalismo, com uma reportagem sobre a expedição da Funai para estabelecer o primeiro contato pacífico com os índios Korubo, na floresta amazônica. Participou de 99 exposições em locais como Kunsthaus, em Zurique; Museo Carillo Gill, na cidade do México; Museo de Bellas Artes, em Caracas; Centro Cultural Banco do Brasil, Centro Cultural Telemar, Museu de Arte do Rio/ MAR e Centro Cultural Justiça Federal, no Rio de Janeiro; e Museu de Arte de São Paulo. Beliel tem obras nos acervos do Museu de Arte do Rio/MAR, do Museu Afro Brasil / SP e da Biblioteca Nacional.

A entrevista com Ricardo Beliel ocorreu num momento em que o Brasil vem sofrendo fortes pressões internacionais por conta da sua atual política ambiental. 
Ricardo Freitas (RF): Olá, Beliel. O que motivou em mim o desejo de entrevistá-lo foi o momento em que me deparei em seu perfil numa rede social com fotos feitas por você na floresta amazônica na década de 1990. Além do impacto estético, me encantei com o texto por você enviado a cada comentário de pessoas que se identificavam com as fotos, com os lugares retratados, com as pessoas retratadas e viam ali um retorno às suas histórias, às suas origens, aos seus passados. Você dizia àquelas pessoas do seu desejo de reunir as suas histórias em um livro, de juntar nesse livro, além das imagens, a história de cada uma daquelas fotos e das pessoas que chegaram nos anos de $1980 \mathrm{e}$ 1990 na Amazônia. Achei esse projeto lindo e acho que podemos começar daqui.

Conta pra gente o que foi esse projeto, porque essas fotos existiram e existem.

Ricardo Beliel (RB): Quando iniciei esse projeto em 1991 eu já tinha visitado a Amazônia diversas vezes, sempre como jornalista, fazendo reportagens sobre questões indígenas, disputas fundiárias, garimpos, meio ambiente, entre tantos outros assuntos. Em 1991, junto com a jornalista Beatriz Cardoso, apresentamos ao jornal 0 Estado de São Paulo um projeto de um caderno sobre meio ambiente, prevendo a realização da conferência ECO-92, no ano seguinte, no Rio de Janeiro. Seria o primeiro suplemento dedicado ao meio ambiente e com esse formato no jornalismo diário no Brasil. Nós dois trabalhávamos na revista Manchete e nos demitimos para assumir a direção desse projeto no Estadão. Infelizmente, $o$ caderno nunca foi publicado, mas fizemos várias matérias que acabaram sendo usadas em outras editorias no próprio Estadão. Uma dessas grandes reportagens foi sobre as questões socioambientais ao longo da rodovia Transamazônica. Alugamos um velho
Gol em Marabá, no estado do Pará, e percorremos o trecho que vai dessa cidade a Itaituba, já quase no estado do Amazonas, indo e vindo, buscando histórias, personagens, ambientes que estavam passando por mudanças - comunidades tradicionais, grupos indígenas, assentamentos de colonos legais e ilegais, projetos do governo que deram certo ou que se atolaram em erros etc. De Marabá a Itaituba são cerca de mil quilômetros. Portanto, calculo que nos dois meses em que nos dedicamos a esse trabalho devemos ter feito cerca de dois mil quilômetros, indo de um lado a outro.

Nesse conjunto de fotos que publiquei no Facebook há também algumas, em menor número, que foram feitas em outros momentos e para outras reportagens, como quando trabalhei com o Greenpeace, no início dos anos 2000, e quando fui a Serra Pelada pela primeira vez.

0 conjunto de fotografias que tenho e desejo usar na edição de um livro é bem maior do que as que usei no Facebook. A vantagem de coloca-las numa rede social foi ter despertado o interesse e as manifestações de pessoas que, hoje, moram nessa região. Assim, pude trocar com elas informações e interesses em comum.

RF: Quais as dificuldades encontradas para fazer essas fotos?

RB: No início dos anos de 1990, a região estava sendo ocupada por levas de imigrantes, grande parte de nordestinos (sobretudo, maranhenses) e alguns gaúchos. Isso provocava muitas tensões e conflitos entre indivíduos e grupos, como, por exemplo, o que aconteceu em Eldorado dos Carajás. A grilagem de terras públicas, a pistolagem ao estilo "velho oeste", doenças, muitas delas desconhecidas dos novos ocupantes, pois tinham suas origens na selva tropical, estradas intransitáveis em vários trechos, com 
riscos de acidentes ou lamaçais intransponíveis, com o risco de ficar atolado por mais de um dia. Em Serra Pelada, ainda nos anos 80, assisti a muita violência, como esfaqueamento e brigas, com mortos e feridos. Nessa reportagem sobre a Transamazônica acompanhamos grupos de índios Parakanã, na selva, para atacar de surpresa invasores de suas terras que estavam cortando madeira ilegalmente. Quando saímos da reserva, passando por Novo Repartimento, fomos ameaçados por "empresários", donos de madeireiras, pelo fato de nos identificarem como "os amigos dos índios que atrapalhavam seus negócios". 0 mesmo aconteceu na reserva dos índios Arara, que tinham o prefeito de Uruará como mentor das invasões de suas terras. Em Tucuruí, o prefeito, ao nos receber em seu gabinete, mandou um assessor colocar no meio da sala um balde abarrotado de esterco e nos disse que dois jornalistas, como nós, vindos do sul do país, "não eram pouca merda, como naquele balde", mas que poderíamos, igualmente, ser jogados na mesma vala. Ou seja, foram apenas alguns riscos...

RF: Caso tenha havido dificuldades, essas dificuldades, hoje, seriam as mesmas ou você acredita que o Brasil contemporâneo te faria encontrar outros obstáculos? Quais?

RB: Eu não voltei a essa região nos últimos dez anos. Não posso falar com segurança sobre como andam as coisas por lá. Mas o modelo de ocupação social desse lugar, que no passado o presidente general Médici apontou como sendo "uma terra sem homens, para homens sem terra", é equivalente à conquista do velho oeste norte-americano, com matanças de índios, lutas por terras, destruição do meio ambiente, avanço da agropecuária, garimpos ilegais, trabalho escravo nas fazendas, pistoleiros, polícias corruptas e violentas etc.
Acho difícil que uma sociedade com esses valores dê certo. Mesmo assim, podemos encontrar pessoas especiais e histórias fortes que nos comovem.

RF: Seria legal se nos dissesse o que entende acerca da possibilidade da imagem, da fotografia, trazer à tona lembranças de um passado, da foto servindo de instrumento à produção de fatos históricos - e, não somente, à apreensão e registro de um momento, sempre, histórico.

RB: Fotografia é a apreensão de um momento fugaz, efêmero, que poderia se dissipar por esquecimentos, por negação da realidade ou por outras versões que defendam interesses contrários aos fatos reais. Trabalhar com fotografias, seja fotografando, colecionando, editando, expondo ou compartilhando em redes sociais, é uma forma muito eficiente de preservar e/ou compreender a História. Acredito ser esse o papel do fotógrafo e do jornalista, entre tantos outros usos que se possa fazer com a fotografia. Por isso, me motivei a recolocar essas fotos em espaços públicos - nesse caso, aproveitando o alcance de uma rede social -, me aproximar dos personagens dessas histórias e assim, quem sabe, poder contar junto com eles as suas experiências de vida e as de seus vizinhos e parentes e, até mesmo, seus desafetos. Há histórias e eu gostaria de contá-las.

RF: O que acha que seria a história desses povoados, vilarejos e, hoje, cidades se não houvesse o registro de imagens em fotografia ou vídeo - como é o caso do seu trabalho. Você acha que haveria uma outra história? Caso afirmativo, qual seria essa outra história? Caso negativo, por que nada mudaria?

RB: No Brasil, há um péssimo hábito de deixar a História pra lá. Infelizmente, esse é um comportamento que se percebe em todas as classes sociais, econômicas e culturais. Passam tratores, tanques, cavalos, 
botinas, indiferença, descaso etc. por cima de qualquer vestígio histórico. Cidades são destruídas, livros de História jogados no lixo, ambientes importantes para as culturas tradicionais são profanados, sítios arqueológicos adulterados, personagens ricos em vivências históricas esquecidos e abandonados (João Cândido, o líder da Revolta da Chibata, é um exemplo) etc. No caso da Amazônia, em especial nessa região do sul do Pará, a cada geração, são novas levas e mais levas de colonos a ocupar essas terras. São como camadas geológicas que se sobrepõe umas sobre as outras. Muita coisa se perde nesse processo. Havia muitos analfabetos quando eu estive lá... Poucas escolas... E hoje, acredito, que mesmo as tradições orais já não têm mais a força que tinham para seus antepassados. A cultura televisiva e, agora com mais força, dos celulares tem influência desagregadora desses vínculos com as origens e experiências vividas por essa nova sociedade que ali se estabeleceu a partir dos anos de 1970.

Através do Facebook obtive respostas que me emocionaram e estimularam a transformar esse conjunto de fotografias em um livro junto com depoimentos, mesmo que pequenos, dessas pessoas. Entre tantos outros, separei alguns": "Verdade! Esse loirinho do lado do Sr. Geraldo é o filho do Ronaldo Chapéu de Couro. Fotografia na esquina, no Açougue do Sr. Geraldo! Bons tempos!" (sic) ${ }^{2}$; "Esse de chapéu é o seu Geraldo do Açougue. Até hoje ele mata porco e o moleque de short azul é o Jocivan e o outro do lado é o Fogoió, filho do Seu Geraldo. Eu tenho uma foto minha neste mesmo local. Pen-

1 Os depoimentos aqui apresentados são postagens feitas por amigos e familiares dos retratados nas fotografias compartilhadas no perfil do fotógrafo na rede social, em 2020.

2 Depoimento de Glauciane Lobo Zaidan. se em um moleque feio. Era eu. Kkk" (sic) ${ }^{3}$; "Os meninos são o Fogoió, filho do Geraldo, o Maninho, filho do Seu Cazuza, e o moreno é o filho do Bigodinho Sapateiro e o outro é filho do Ronaldo Chapéu de Couro" (sic) ${ }^{4}$; "Meu Deus. Que emoção ver minha vozinha. Obrigada de coração por essa lembrança. Vou guardar pra sempre" (sic) ${ }^{5}$; "Hoje só saudades nossa vizinha dona Zenaide. Viemos na mesma carrada, éramos oito famílias. Até hoje o lembrar tudo o que passamos parece mentira, meu querido pai que também não está mais entre nós e muitos que já se foram. Meu Deus!!!” (sic) ${ }^{6}$; "Verdade Magna Paixão, esse velhinho era osso duro de roer, mais essa foto me deixou emocionada muito linda, viajei ao passado quando ele esteve os últimos dias de vida ao nosso lado. Meu avô foi meu Herói. Grata a vc Ricardo Beliel pela foto ficou linda e me trouxe belas recordações" (sic)7; "Essas pessoas da foto são meus avós, meus tio quando criança e meu primo, minha avó de blusa lilás, minha tia ao lado dela e meu avô sentado com meu tio e primo... recebi essa foto hoje, emocionada de ver essa imagem, minha avó já não está mais conosco... muita saudade. Nossa, bons tempos esses, tempos que eramos felizes com pouco que tinhamos" (sic) ${ }^{8}$; "Nossa... lembranças boas e ruins. Nossa quase morria nesta ladeira da velha grávida o carro desceu nossa foi um susto muito grande. Que custou a vida do meu filho. Morava em Pacaja aonde fui criada. Estava indo pra Tucuruí. Nossa lembranças parece que estou vivendo este momento"; "Meu avô tombou um caminhão nessa ladeira quase matou a

3 Depoimento de Jocimar Oliveira.

4 Depoimento de Dernival Da Silva Lima Lima.

5 Depoimento de Teresinha Martins.

6 Depoimento de Gildean Melo.

7 Depoimento de Jane Gleide.

8 Depoimento de Jaqueline Rodrigues.

9 Depoimento de Dalva Santt'os. 
familia inteira” (sic) ${ }^{10}$; “Já passei uma semana dormindo numa rede atada atrás da carroceria do caminhão do meu pai, que quebrou no pé dessa ladeira. Em 1997. Famosa Ladeira da Velha. Muita história. Fantástico" (sic) ${ }^{11}$; "Escolinhas feita pelos moradores ajudamos embarriar a nossa no $\mathrm{Km} 320$ nossos pais no mutirão para fazer a escola e os filhos ajudando. Depois vinha os politicos pedir voto sem nada fazer" (sic) ${ }^{12}$; "Eu mim reconheço em todas essas fotos minha vida minha história embora não estou em nenhuma mais mim orgulho de um dia ter vivido um pouco de cada imagem" (sic) ${ }^{13}$; "Apesar de ter passado vários anos mais alguns conflitos permanecem tais como: conflitos agrários, falta de compromisso dos nossos governantes" (sic) ${ }^{14}$; "Eu nasci nessa região na Transamazônica lá em Uruará. São terras boas muito produtivas cacau, castanha do Pará, cupuaçu pimenta do reino, só que são um povo muito sofrido nos tempos de chuvas Muito muitos atoleiros" (sic) ${ }^{15}$; "São lindas as imagens, mas causa tristeza, tem aspecto de sofrimento, em saber que muitos ainda vivem assim..." (sic) ${ }^{16}$; "Quanta pureza no ser humano. A época" (sic) ${ }^{17}$; "Beliel vc dá aulas todo dia. Sem atacar ninguém. Sem se defender. Imagens descrevem tantas coisas... assim como palavras que ninguém entente. Imagem é muda, olhos vêem e ninguém escuta" (sic) ${ }^{18}$.

RF: Quais suas considerações acerca da Internet servindo à reunião de pessoas, ao compartilhamento de histórias? Tanto Eu como seus interlocutores nos comentários

10 Depoimento de Ana Flavia Poubel.

11 Depoimento de Julio Kalb.

12 Depoimento de Marlene Coimbra.

13 Depoimento de Katia Damasceno.

14 Depoimento de Maria José De Souza.

15 Depoimento de Jurandir Santos.

16 Depoimento de Angela Medeiros.

17 Depoimento de Ilmar Oliveira Chagas.

18 Depoimento de Cristiano Marins. abaixo das postagens (e vi que todas as fotos têm comentários de familiares e/ou amigos dos retratados) nos encontramos ali, naquelas fotos, por conta do advento da Internet. Fale mais disso.

RB: A internet tem uma força de comunicação que me impressiona. Quando coloquei as fotos no Facebook, imaginava que iria atingir apenas a minha rede de amigos ou, talvez, um pouco mais de pessoas que também têm interesse nesse tema. Mas, nem pensava em alcançar os moradores de lá. Quando notei que vários comentários e curtidas eram feitos por gente da região, parentes e até mesmo quem eu havia fotografado, percebi que tinha aberto um canal de comunicação com eles e poderia interagir, sugerir coisas e, principalmente, devolver a eles essas imagens. Quando eu fiz essas fotografias, não havia internet e muitas dessas comunidades nem correio tinham por perto. Será muito bom se eu conseguir provocar essas reminiscências, emoções, articulações sobre suas histórias e se, juntos, construirmos um trabalho de preservação de tudo isso. Estimulei ao máximo que me enviassem informações, escrevessem sobre eles e seus parentes e me identificassem algumas das fotos. Alguns responderam, deram informações, mas de forma geral percebo que eles têm dificuldade em escrever, formular narrativas, lembrar de fatos e até mesmo contar "causos". De qualquer forma, me impressionei com o alcance desse material no Facebook. Houve, até o momento em que escrevo, 8.141 compartilhamentos, 3.551 curtidas e 311 comentários.

RF: Muitas das suas fotos, nisso que vou chamar de série Amazônia, falam da chegada do homem à floresta, do povoamento da floresta. Mas, e talvez por isso, também falam do desmatamento, do desflorestamento. Nesse sentido, fiz a leitura de que sua 
arte serviu, ali, a uma causa, a uma denúncia.... Social, ambiental, política. Você acha que a arte tem esse papel político, militante, engajado? Você acredita que a arte pode estar articulada com o ativismo político, um tipo de artivismo?

RB: Embora eu tenha participado de mais de cem exposições, entre individuais e coletivas, em centros culturais, museus e galerias por muito tempo, não me assumi como artista. Por mais de quarenta anos, trabalhei como jornalista, fotografando e escrevendo, e minha principal galeria eram os meios de comunicação para os quais eu trabalhava. Como jornalista acho fundamental estar comprometido com a vida, com um esforço em melhorar nossas sociedades, aperfeiçoar nossas existências, respeitando nossas fontes e nossos leitores/espectadores. Quanto à arte, creio que não deve estar presa a essas convenções, obrigações e amarras. A arte deve ser livre, mas o artista, como cidadão, com senso crítico e comprometido com uma ética da felicidade democrática e plural, deve se posicionar sim. Talvez e, não obrigatoriamente, com sua arte, mas, sobretudo como pessoa que se preocupa com o mundo em que vive. Meu trabalho é uma mistura dessas duas observações, a jornalística e a artística. Sou uma mistura de tudo isso.

RF: Ainda aqui, o que acha da arte desinteressada, que não defende nenhuma outra causa que não seja a contemplação do belo, propriamente? Ou seja, você acha que é papel da arte falar em seus termos políticos ou a saída seria a produção de uma arte pela arte?

RB: A História da Arte nos responde isso. Há tantas coisas belas, impactantes, eternas que foram feitas com propósitos tão diferentes, opostos até, e que nos tocam de formas tão profundas... Não há um consenso entre teóricos da arte, artistas, críticos, filósofos, professores, apreciadores, etc. sobre o que é e para que serve a arte. Há opiniões totalmente divergentes sobre isso. A arte serviu às religiões e tem exemplos fantásticos, a arte foi influenciada por diversas filosofias e tem exemplos fantásticos e antagônicos em suas visões, a arte serviu e serve para embelezar a vida, e que bom que podemos usufruir da beleza, a arte serviu a pensamentos e ações políticas e que bom que pode transformar o mundo, a arte serve para libertar a alma e salvar-nos do desespero. Quantos loucos foram e são grandes artistas? E eles nunca estiveram preocupados com a "função da arte na sociedade". De preferência a arte deve ser livre e a liberdade é revolucionária.

RF: Qual você acha que são as contribuições dessa série Amazônia para o Brasil hoje? 0 que mudou nessas três décadas?

RB: Eu sou pessimista em relação ao Brasil. Acho que estamos piorando. 0 avanço da sociedade dita "civilizada" com seus desejos de consumo desenfreado, de lucro a qualquer custo, do uso indiscriminado da violência, dos preconceitos raciais e de gênero, o pouco cuidado com o meio ambiente etc. As questões, mal resolvidas, do lixo e do saneamento básico são exemplos gritantes de quanto não melhoramos nada. As instituições políticas estão dominadas por máfias de todos os tipos. Os defensores da Terra e da Humanidade são assassinados diariamente. E o que vemos de mudanças é, de forma geral, o consumismo cada vez mais frenético e o culto às vaidades, deslocando o sentido de nossas existências para um limbo de "falsa felicidade". Tenho saudade de um Brasil mais saudável. 

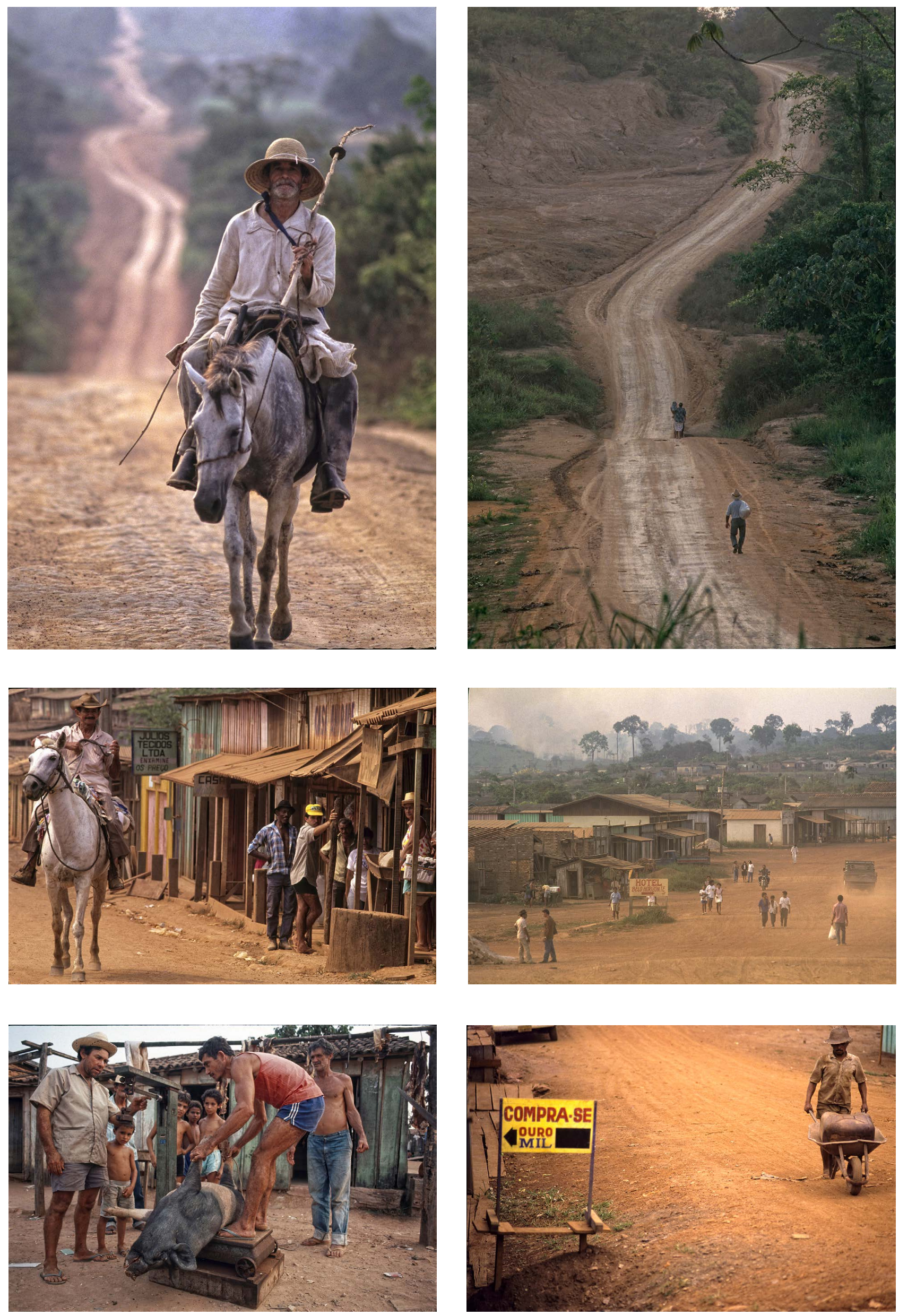

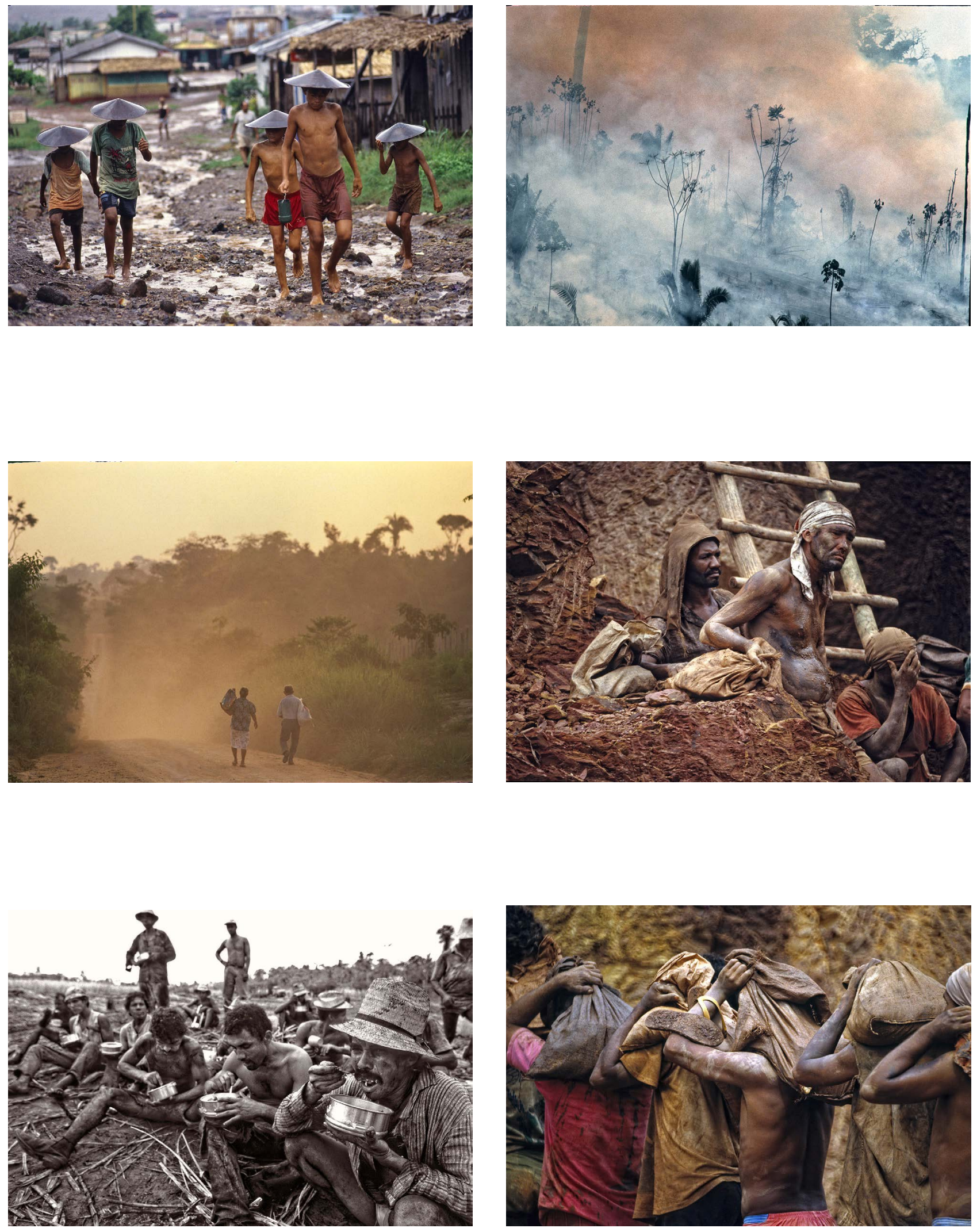